\section{Astronomical explanation of the enigmatic sundial in Agra, India}

\author{
Aalok Pandya ${ }^{1,4, *}$, Tej Bahadur ${ }^{2}$ and \\ Sandip Bhattacharya ${ }^{3,4}$ \\ ${ }^{1}$ Department of Physics, JECRC University, Jaipur 303 905, India \\ ${ }^{2}$ Manipal University, Jaipur 303 007, India \\ ${ }_{3}^{3}$ B. M. Birla Planetarium, Statue Circle, Jaipur 302 001, India \\ ${ }^{4}$ Astronomy and Astrophysics Resource Development and Research \\ Academy, Jaipur 302 001, India
}

This study explains the functioning of a sundial in Moti Masjid, a mosque in Red Fort, Agra, India. The instrument, made in Islamic style, had remained enigmatic for a long time. The present study is an effort to resolve this enigma. The gnomon length for the sundial is ascertained and its functioning has been examined using on-site observations as well as computations.

Keywords: Azimuth, meridian, sundial, time-keeping, zenith.

THE present study describes a sundial in Moti-Masjid, Red Fort, Agra, India (Figure 1). This is a follow-up of our recent exploration of sundials in Srirangapatna, Karnataka ${ }^{1}$ and is in continuation of our explorations of sundials and time-keeping instruments that are yet to be understood and documented ${ }^{1,2}$. There has been a pertinent view in the scientific community, including the reviewers of the earlier communication ${ }^{1}$ that we must explore the functioning of an Islamic sundial that is located in the north of Tropic of Cancer and study the shadow pattern of its gnomon.

Sarma $^{3}$ has catalogued about 580 sundials and various other astronomical instruments of historical importance in India. Many of the sundials mentioned in this catalogue are not scientifically well-explored, and their functioning and underlying concepts need to be studied further.

Moti Masjid was constructed sometime during AD 1638-1673. The sundial under study is said to be set up in this period ${ }^{3}$. It was first explored by J. T. Boileau of the Bengal Engineers in AD 1833 (ref. 3). He published a short explanation of the dial in 1833 along with a sketch $^{4,5}$. These explanations do not shed any light on the actual functioning of the sundial. This sketch by Boileau ${ }^{5}$ gives a brief account of the studies made till then as follows: 'The absence of any graduation on the dial, this object engraved with a nearly circular arc has never been elaborately explained. This leads only to a supposition that the dial was meant only for indicating Muslim prayer times. Although many celebrated Maulavis have visited the Moti Masjid and examined the sun-dial as it stands, it is not fully understood. ${ }^{4}$

\footnotetext{
*For correspondence. (e-mail: aalok.pandya@igntu.ac.in)
}

With no inscriptions or indications of direction, the dial is installed on a $\sim 36$ inches high pedestal. GPS readings of the site are $27^{\circ} 10^{\prime} 49^{\prime \prime} \mathrm{N} ; 78^{\circ} 01^{\prime} 10^{\prime \prime} \mathrm{E}$ and altitude $115 \mathrm{~m}$.

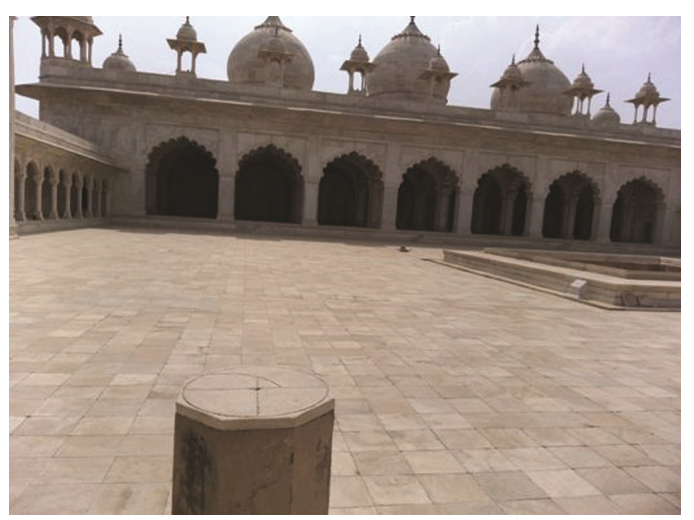

Figure 1. Sundial on a raised platform in Moti-Masjid, Agra, India.

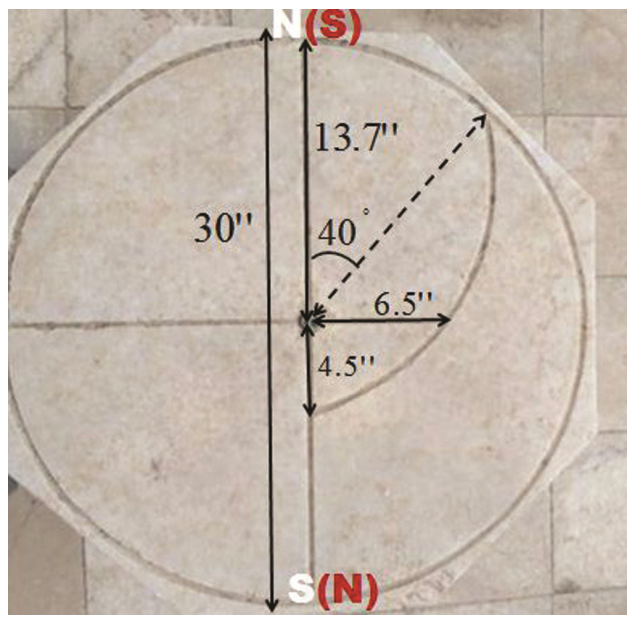

Figure 2. Dimensions of the sundial.

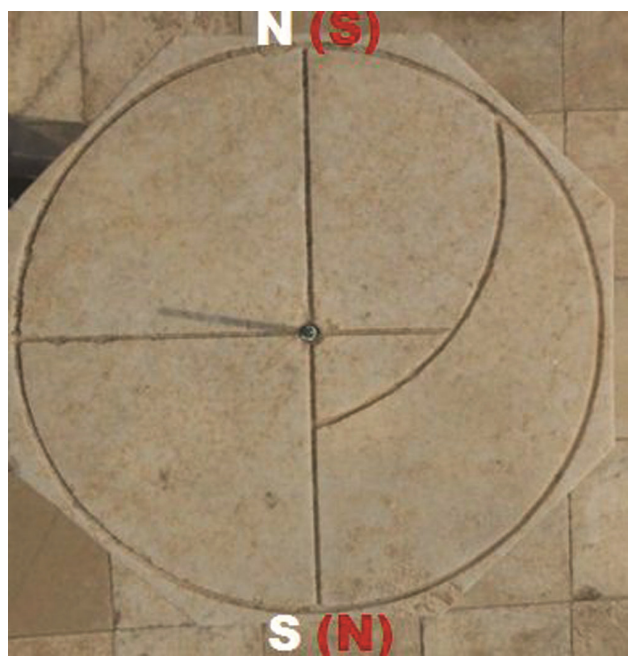

Figure 3. The shadow of a make-shift gnomon at prayer time of Asr (03:49 pm on 21 June 2018). The afternoon shadow forms on the western side of the meridian line instead of the eastern side. 


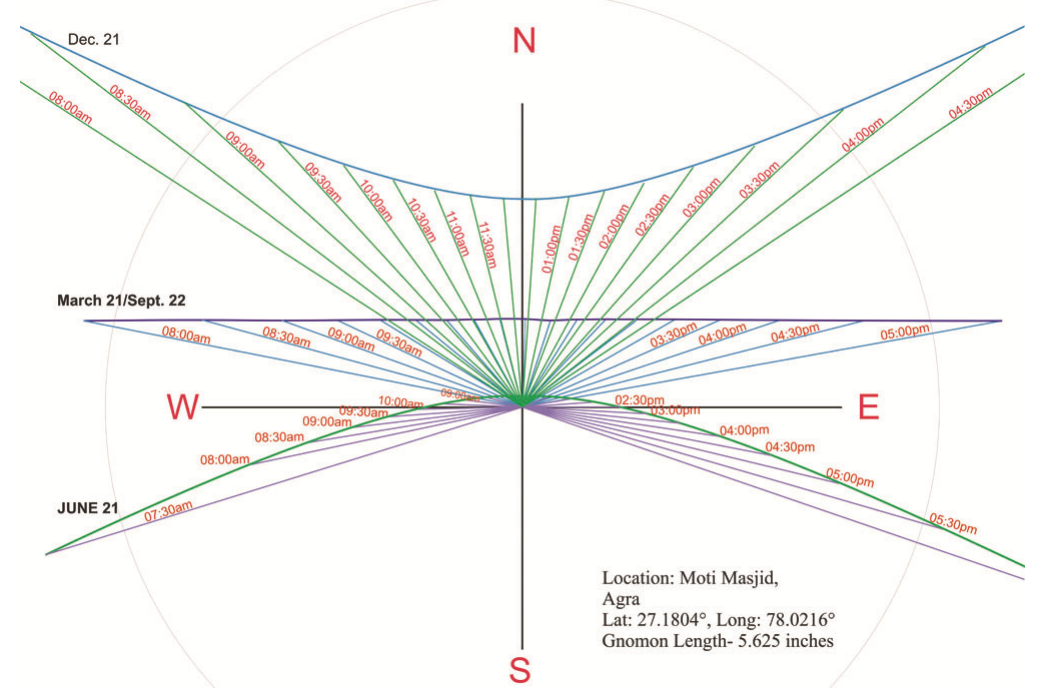

Figure 4. Hourly variation of shadow length on four astronomically significant days of a year.

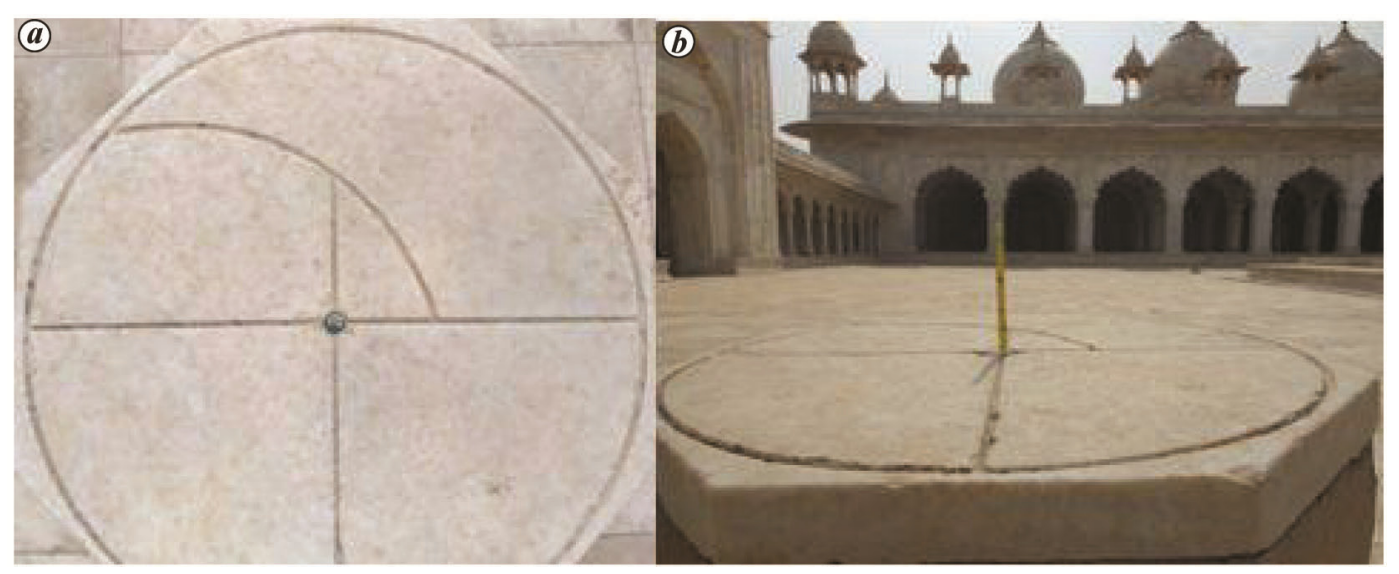

Figure 5. Observations of shadow pattern from different angles. $\boldsymbol{a}$, Almost shadow-less moments at the zenith, the indicator of prayer of Zuhr (12:20 pm on 21 June 2018). b. Shadow of the gnomon at the time of Asr (03:49 pm on 21 June 2018) with the mosque in the background.

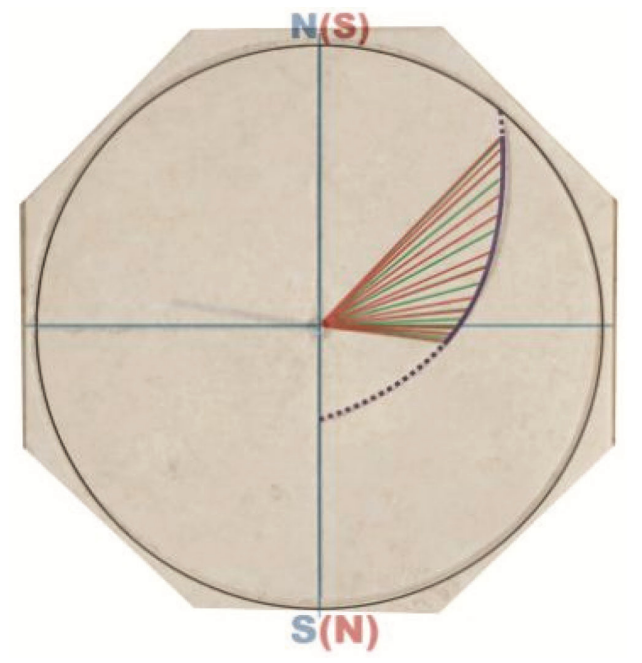

Figure 6. Overlay of the computed shadow pattern at Asr on the image of the sundial.
The lines and arcs engraved on an octagonal marble slab are not sharp and are almost quarter inch or $\approx 4 \mathrm{~mm}$ thick (Figure 2). The engraved circle on the dial has a radius 13.7 inches and the two opposite sides of the octagonal dial are $\sim 30$ inches apart. The north-south line of the sundial coincides well with the local north-south meridian line. However, the dial sits in exactly $180^{\circ}$ opposite orientation. Annotations in white colour in Figures 2 and 3 indicate the true direction that ought to be, whereas, annotations in red colour indicate the present (wrong) orientation. Our magnetic compasses and noon shadow observations confirm this. The distortion must have been made, perhaps in the 19th century, even before 1833 .

A careful study of the sketch of Boileau reveals that the dial sits with wrong orientation; it was wrongly oriented even in 1833.

We now explore the style and dimensions of a gnomon of the sundial and its possible functioning. The shallow 


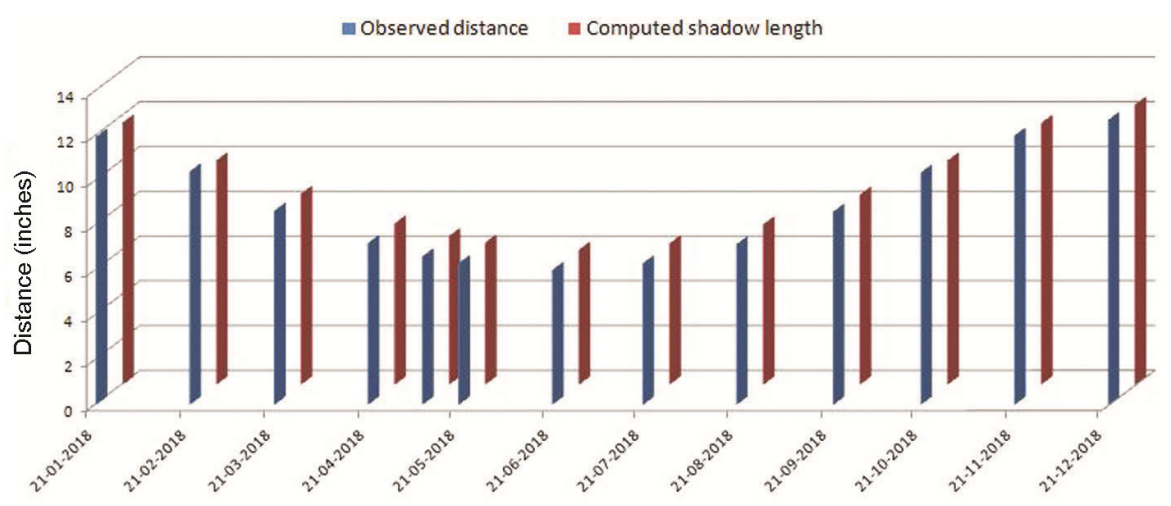

Figure 7. Comparison between observed distance on the inscribed curve and the computed shadow lengths.

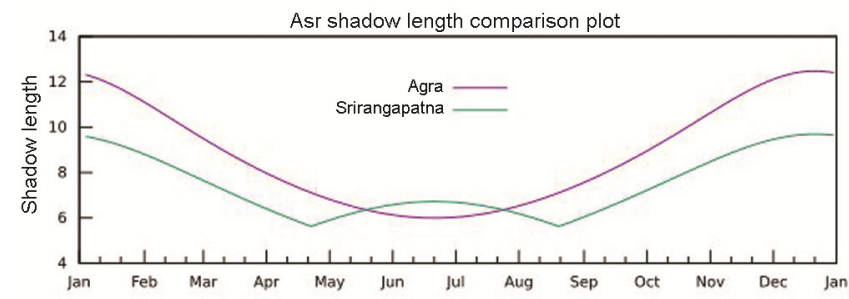

Figure 8. Yearly variation of Asr shadow lengths with respect to azimuth at tropical (Srirangapatna, Karnataka) and subtropical (Agra) locations for a common gnomon length of 5.625 inches in both cases.

cavity at the centre of the dial was meant to place a missing vertical gnomon. With our earlier experience ${ }^{1}$, it was evident that the arc engraved inside the circle represents the locus of the gnomon's shadow tip, indicating the afternoon Asr prayer time throughout the year. When the shadow of a gnomon touches the curve, it is time for Asr. In Islamic practice, the prayer time of Asr starts when the shadow length of the gnomon is equal to its own length plus the shadow length at local noon ${ }^{1,6,7}$.

Since there is no inscription on the dial, we were not aware of what the gnomon length should be. We therefore did reverse engineering as follows: we computed the shadow lengths of an assumed gnomon length of 6 inches for Asr throughout the year. Our computation indicates that the shadow length of the gnomon is $6 \frac{1}{2}$ inches on 21 June (summer solstice) at the time of Asr around 03:49 pm (IST) and the shadow subtends an angle of $\sim 97.5^{\circ}$ towards the east with the north-south line.

During our visit to the site on a summer solstice day, we marked the angle of $97.5^{\circ}$ with the meridian line on the dial from the centre of the dial where the shadow is supposed to meet the Asr arc. The gnomon shadow lay exactly $180^{\circ}$ opposite the marked line at the designated prayer time for the day. However, the shadow length was measured as 6 inches. Reverse computing revealed that a gnomon length of 5.625 inches ( $5 \frac{5}{8}$ inches) would cast a shadow of that length at an azimuth angle of $97.5^{\circ}$ at around 03:49 pm (IST) in Agra on 21 June.

Given the celestial coordinates of the Sun throughout the year, its shadow length can be computed for Agra for a given gnomon length of 5.625 inches ( $5 \frac{5}{8}$ inches). We computed and plotted the hourly variation of gnomon shadow for astronomically significant days of a year ${ }^{8}$ (Figure 4).

It is imperative to mention that the sundial with no other graduation is relevant only for Islamic prayer, particularly the midday prayer Zuhr and the afternoon prayer Asr (Figure 5).

We traced the locus of the tip of shadow lengths throughout the year at the prayer time of Asr and we obtained an arc that mimics the Asr arc engraved on the dial. If this arc is superimposed on the image of the dial, the computed arc matches fairly well the Asr arc engraved on the dial (Figure 6). The maroon line in Figure 6 is the locus of the shadow tips that indicates the beginning of Asr throughout the year. We need to note that the dotted part on the computed arc in Figure 6 is practically never observed. The designers of the dial may have stretched the arc on both sides for the sake of aesthetics. Figure 6 also clearly highlights the wrong orientation of the dial, as the gnomon casts its shadow in the opposite direction. Here, the present (wrong) direction and the annotation in blue colour indicate the correct orientation that ought to be.

We also computed the error between the observed distance on the dial and the computed shadow length. Figure 7 shows a graphical presentation of the same.

The minimum error was found to be zero and maximum error was $4.01 \%$.

We also carried out an exercise to compare the sundial in Srirangapatna with the dial in Agra, and plotted the variation in shadow length with variation in azimuth for 12 months (Figure 8).

The shadow curve for locations above the Tropic of Cancer bottoms out just once in a year. The same, however, bottoms out twice during the year in the tropics. This indicates the solar zenith passage occurring twice between the tropics during the year. The closer a location is to the equator, the farther is the separation between the two minima. At the equator, these minima coincide with the equinoctial dates. At the Tropic of Cancer, both the 


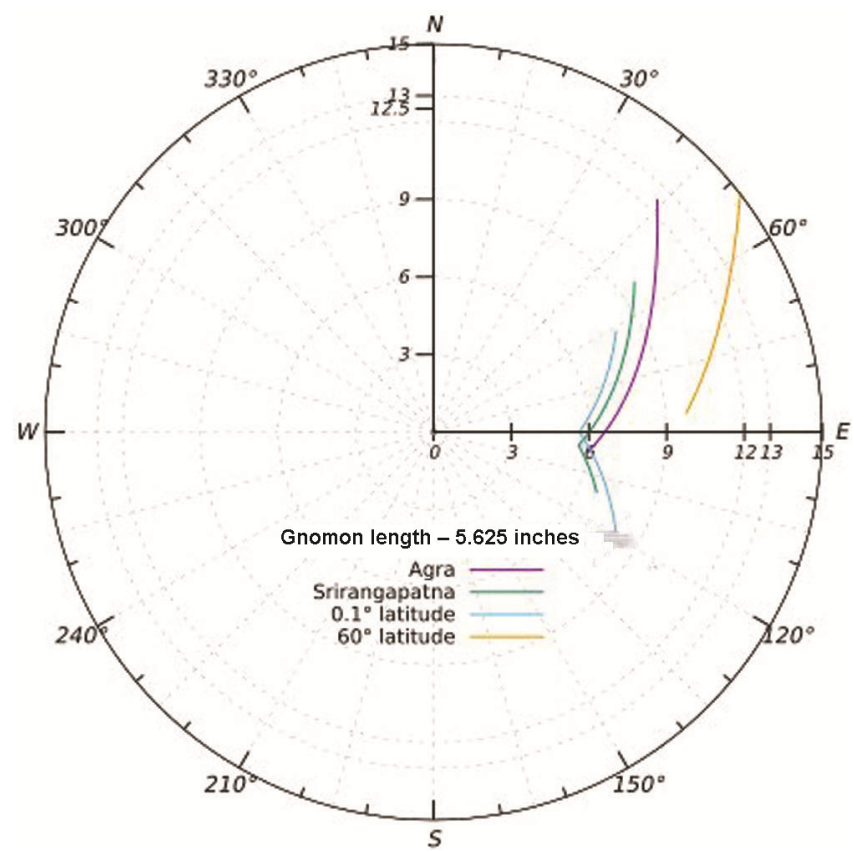

Figure 9. Comparative representation of Asr curve for different latitudes.

minima coincide on the summer solstice day. A similar coincidence happens on the winter solstice day at the Tropic of Capricorn.

Figure 9 shows a more realistic representation in polar coordinates, including additional azimuthal data for places from the equator to $60^{\circ}$ lat., exhibiting interesting shape change of the Asr curve.

The Moti Masjid sundial, though a fine piece of art, has been useless for centuries and in wrong orientation. Because of its simple, single Asr curve, the dial is also significantly different from the one at Srirangapatna ${ }^{1}$. Srirangapatna, being situated in the tropics, witnesses the Sun's zenithal passage twice a year. The size of the lower part of the Asr curve beyond the cusp signifies how close the place is to the tropical lines. Since the Sun never reaches the zenith beyond the tropics, the lower part of the Asr curve disappears.

The Asr prayer time in Agra practically extends up to sunset. It is time for the fourth prayer-Maghrib at sunset. We could successfully determine the appropriate length 5.625 inches of the missing original gnomon of the sundial in Agra by carrying out computer simulations, followed by on-site observations to resolve a longstanding puzzle.

1. Pandya, A., Tej Bahadur and Bhattacharya, S., Astronomical significance of sun-dials in Srirangapatna. Curr. Sci., 2018, 116(5), 811-816.

2. Pandya, A., Tej Bahadur and Bhattacharya, S., Sun-dial for timekeeping in Jaisalmer Fort. Indian J. Hist. Sci., 2017, 52(2), 137-146; http://insa.nic.in/UI/Journalarticle.aspx?jid=Mw==\&\&VID=MzMw$\& \& \mathrm{IsNm}=\mathrm{SXNzdWUgMg}==$

3. Sarma, S. R., A Descriptive Catalogue of Indian Astronomical Instruments, 2017, pp. 3602-3604 and references therein; http://www. srsarma.in/catalogue.php
4. Ibid; pp. 3603-3604.

5. King, David A., Astronomy and Islamic society: Qibla, gnomonics and timekeeping. In Encyclopedia of the History of Arabic Science (ed. Roshid), 1996, vol. 1, pp. 128-184, 166-167.

6. Karim, A. S. M., A Guide to PRAYER in Islam, The Co-operative Office for Call and Foreigners' Guidance at Sultanah, Riyadh, 1997, pp. 16-17; http://www.islamicbook.ws/english/english-020.pdf

7. http://praytime.org/calculation

8. http://astronomyaardra.org/Astronomy\%20Resources/sun-ra-dec.f.

ACKNOWLEDGEMENTS. We thank the Archeological Survey of India, New Delhi for permission to visit the site. We also thank the staff and attendants at the Red Fort, Agra, for assistance.

Received 2 June 2019; revised accepted 4 January 2021

\section{Traditional knowledge of medicinal plants among the Thangal-Naga ethnic group of Manipur, India}

\section{Babina Pampuinath and Maibam Dhanaraj Meitei*}

Department of Forestry and Environmental Science, Manipur University, Canchipur 795 003, India

With a population of 4475 individuals, the ThangalNaga of Manipur is one of the vulnerable schedule tribe groups in India. During the study, oral traditional knowledge for the treatment of ailments using wild medicinal plants by the ethnic group was documented. Forty-one ethnomedicinal plants from 40 genera and 28 families were reported during the semistructured interviews of 70 locals. In total, 29 different ailments were treated using medicinal plants. Further, phytochemical analysis of 11 common medicinal plants revealed the presence of alkaloids, flavonoids, saponins, tannins, phenols, steroids, anthraquinones, coumarins, glycosides and terpenoids.

Keywords: Ethnomedicinal plants, ethnic groups, photochemical analysis, Thangal-Naga, traditional knowledge.

THANGAL-Naga, also known as Koirao, is one of the endangered, small, tribal ethnic groups in India with a population of 4475 individuals, and represents $0.38 \%$ of Manipur's tribal population ${ }^{1}$. Today, there are only 11 villages in Senapati district of Manipur, viz. Angkailongdi,

*For correspondence. (e-mail: maibam.meitei@yahoo.in) 